\title{
Concomitant loop diuretics and ACE inhibitors increase risk of lithium toxicity in elderly people
}

Juurlink DN, Mamdani MM, Kopp A, et al. Drug-induced lithium toxicity in the elderly: a population-based study. J Am Geriatr Soc 2004;52:794-8.

\section{Q In elderly people, is lithium toxicity associated with concomitant use of diuretics, angiotensin converting enzyme inhibitors, or nonsteroidal anti-inflammatory drugs?}

METHODS

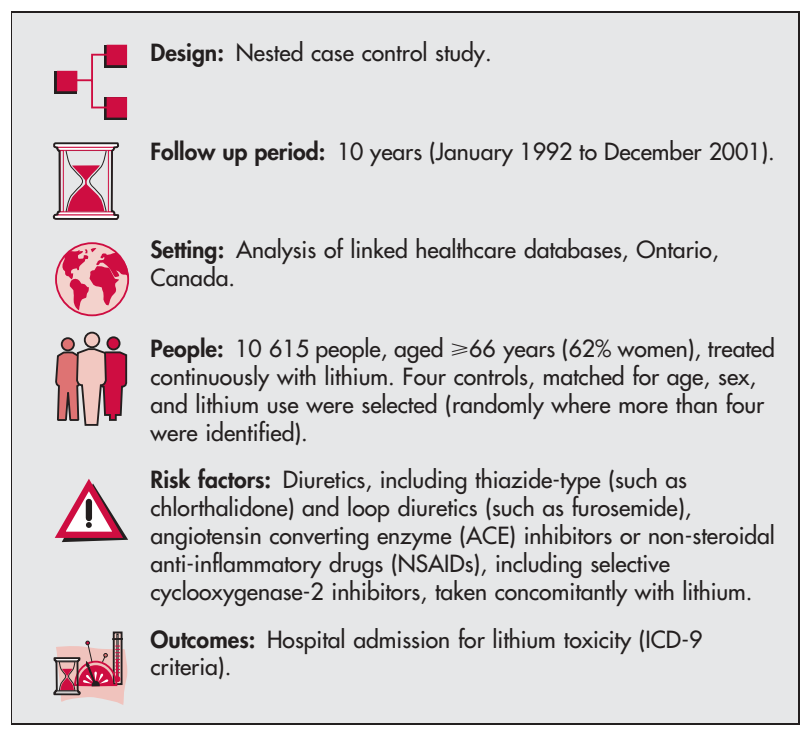

\section{MAIN RESULTS}

Over 10 years, 413 people (4\%) receiving continuous treatment with lithium were admitted into hospital at least once for lithium toxicity. Of these, $15 \%$ required critical care, $3 \%$ dialysis, and $5 \%$ died before discharge. Existing use of loop diuretics and ACE inhibitors was associated with a modestly increased risk of lithium toxicity. Initiating loop diuretics or ACE inhibitors significantly increased the risk of lithium toxicity: within one month of starting treatment. Hospitalisation was almost six times more likely for people initiating loop diuretics, and four times more likely for those initiating ACE inhibitors compared with case controls (see table). Thiazide diuretics and NSAIDs were not associated with an increased risk of lithium toxicity in both new and existing users.

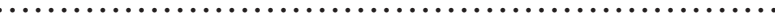
For correspondence: David Juurlink, G-wing, Sunnybrook and Women's College Health Sciences Center, Bayview Avenue, Toronto, Ontario, Canada; david.juurlink@ices.on.ca

Sources of funding: the New Engineering Team Grant from the Canadian Institutes of Health Research.
Table Relative risks of hospitalisation for lithium toxicity and association with other medications

\begin{tabular}{lll}
\hline $\begin{array}{l}\text { Treatment begun } \\
\text { within } 28 \text { days }\end{array}$ & All users (RR, 95\% Cl)† & New users (RR, 95\% Cl) $\dagger$ \\
\hline $\begin{array}{l}\text { Thiazide diuretics } \\
\text { Loop diuretics }\end{array}$ & $1.3(0.7$ to 2.5$)$ & $1.3(0.3$ to 4.7$)$ \\
ACE inhibitors & $1.6(1.1$ to 2.7$)$ & $5.5(1.9$ to 16.1$)$ \\
NSAIDs & $1.1(0.8$ to 1.6$)$ & $0.6(2.6$ to 22.0$)$ \\
\hline
\end{tabular}

tRRs adjusted for other potential interacting medications.

\section{CONCLUSIONS}

Loop diuretics and ACE inhibitors taken concomitantly with lithium significantly increase the risk of lithium toxicity within one month of beginning treatment.

\section{Commentary}

A glance at the latest British National Formulary ${ }^{1}$ shows that the potential for diuretics and ACE inhibitors to cause lithium toxicity is well known. This excellent paper not only provides robust evidence for it, but also points to the need to refine advice to clinicians. It is probably true to say that most geriatricians and old age psychiatrists believe that angiotensin converting enzyme (ACE) inhibitors, diuretics and non-steroidal anti-inflammatory drugs (NSAIDs) should be prescribed with extra care to elderly patients taking lithium. What this paper shows is that ACE inhibitors newly prescribed (that is, within the last month) to those already taking lithium carry the greatest risk of toxicity $(\mathrm{RR}=7.6)$

A more important new finding is that, where diuretics are concerned, it is loop not thiazide diuretics that carry the greater relative risk $(R R=5.5)$ for older people-the very opposite of what is stated in the BNF (page 652), "loop diuretics safer than thiazides", which may be true for younger patients but not any more for older ones.

Taken at face value, this paper might indicate that thiazide diuretics and NSAIDs are relatively safe to prescribe to patients taking lithium; not that the authors actually suggest it. However, the clinician would be wise to reserve judgement and consider the possibility of a type II error or other more subtle reasons for caution. For instance, a thiazide diuretic prescribed in a long, hot summer to an elderly person whose arthritis makes it difficult to get to the tap (faucet) for water can have the same result of toxicity as a loop diuretic in winter.

Robin Jacoby, DM, FRCP

Professor of Old Age Psychiatry, University of Oxford, Oxford, UK

1 British National Formulary No 47. London: The British Medical Association and the Royal Pharmaceutical Society, March 2004. 